\title{
The Potential of Dark Purple Scented Rice- From Staple Food to Nutraceutical
}

\author{
KANGABAM RAJIV DAS ${ }^{1}$, KANGABAM MEDHABATI2*, \\ KHUMUKCHAM NONGALLEIMA ${ }^{2}$ and HUIDROM SUNITIBALA DEVI ${ }^{2}$
}

\author{
1Department of Environmental Biotechnology, Bharathidasan University, \\ Tiruchirappalli- 620024, Tamil Nadu, India. \\ ${ }^{2}$ Medicinal Plants and Horticultural Research Division, Institute of Bioresources \\ and Sustainable Development, Takyelpat, Imphal-795001, India.
}

http://dx.doi.org/10.12944/CWE.9.3.38

(Received: August 18, 2014; Accepted: September 16, 2014)

\begin{abstract}
Among the rice varieties, Purple Rice has an incredibly rich history and counts among its strains one variety known as Imperial rice as they are reserved for the Emperor's consumption only. The purple color is due to high anthocyanin content, a trait most typically observed in fruits. There are abundant benefits including medicinal properties of rice. Its medicinal properties being imparted by the phytochemicals present in it, some of the important compounds which are worth mentioning are tocotrienols, gamma amino butyric acid, oryzanol, rice bran saccharide, Lutein, Zeaxanthin, butylate hydroanisole, phytosterol. Chakhao, the aromatic black glutinous rice in Manipur, India has an aesthetic value and nutraceutical properties. There is a huge demand in the domestic market, having possibilities for export, thus, it is a need for the improvement of these cultivars for higher production, productivity without losing grain quality characteristics, and its applications in pharmaceutical sciences. In this review, we focus on the nutritional values of rice with nutritional properties and their impact on human health.
\end{abstract}

Key words: Chakhao, Nutraceutical, Black rice, Gamma amino butyric acid, Rice bran saccharide.

\section{INTRODUCTION}

Among the important crops, cereals are one of the economic commodities worldwide. They provide better public health with the main essential food ingredients and nutrition. It is known that consumption of plant-based food, including fruits, vegetables, whole grains, cereals and nuts as well as marine foods plays a key role in disease prevention and health improvement. Rice (Oryza sativa L.) a cereal crop is the major staple food sources for half of the world population. With an average annual population growth rate of $\sim 1.5 \%$ and estimated per capita consumption of about 250 grams of rice per day, the demand for rice is expected to increase to $40 \%$ by 2025 (Gurdev, 2014). Agriculture plays an important role in the economy of the India with annual GDP of $14.5 \%$, which is the single largest while in developed nations; agriculture contributes only $5 \%$ (Singh et al., 2013). The popularity of rice is that it is easily digested, provide protein required for human health and provide a number of operative 
properties. Asian countries lead the consumption of rice with 2 billion people getting $80 \%$ of their energy requirements including carbohydrates $(80 \%)$, protein $(7-8 \%)$, fats and fiber (3\%) (Juliano, 1985). A number of researches have identified the need to increase the yield of the rice, by-products including rice bran and improving nutraceutical properties. Nutraceutical is defined as a part of food or foods that provides benefits to human health by preventing or decreasing the chances of diseases (Brower, 1998). Stephen Defelice coined the term nutraceutical in 1989 (Stephen, 2002) from the two words nutrition and pharmaceutical. There was no regulatory definition for nutraceutical in marketing industries (Zeisel, 1999). The $\gamma$-oryzanol (oryzanol), an important compound has shown lower of blood cholesterol and reduces levels of cholesterol in liver (Rohrer and Siebenmorgen, 2004). Antioxidants from rice help in slowing the onset of diabetes and Alzheimer's disease, and play a role in the prevention of heart disease and cancer (Adom and Liu, 2002). The present review is on the historical background, importance in dietary, medicinal values, phytochemical and importance of black rice, improvement and future concern. We discuss opportunities of dark purple scented rice including Chakhao, which can hold a promising area of research with aims at sustainable utilization of this staple crop to meet the nutritional and dietary requirement for solutions for the grand challenges in global health.

\section{Medicinal Value of Rice}

A number of researchers have been carried out to study the unique properties of rice including that of ancient Indian Ayurvedic literature. The ancient literatures highlighted the important role of Asian countries including, China, Indonesia, India, Malaysia, Myanmar and Thailand for using rice for medical treatment and as mainstay food. Oriental writing has specially mentioned the whole brown rice as the perfect food. The Chinese people have known the medicinal properties of rice from 2800 BC, when the Royal Chinese physicians used it for healing purposes and believed that it helps in restoring tranquility and peace to upset people. The dried, sprouted rice grains were used to increase digestion, muscle toning and expels of gas from the stomach and intestines. The Chinese have a rich knowledge on the uses of rice. The rice is used for strengthening spleen, stomach, increase appetite and cure indigestion. Similarly, in most of the Asian countries, rice is most commonly used for various treatments including traditional Malaysian used boiled rice as eye lotion and for acute inflammation of inner body tissue. Powder rice is used for skin ailments. The Cambodian uses the matured plants hulls for treating dysentery and diuretic cases. People of the Philippines use rice polish know as bran, (Tiki tiki) as an excellent source of vitamin $\mathrm{B}$, to cure and prevent beri beri disease (Vir et al., 2005), malnutrition and chronic diseases (Dipti et al., 2012). In India, rice plays an important role from the ancient times where the great saga Parashara has written in Sanskrit that rice is vitality, rice is vigor too and rice indeed is the means of fulfillment of all ends of life. All, Gods, demons, and human beings subsist on rice (Majumdar and Banerji, 1960). The medicinal properties are very rich among the Indian communities including in Telugu folk song (Raju, 1984). Epidemiological studies of rice have shown the antioxidant properties reduce the damage in bimolecular structures, which play an important role in prevention of chronic diseases.

\section{Phytochemical of Rice and Rice Bran}

Research on rice phytochemicals has identified that rice bran, the outer layer of rice grain is a rich source of gamma-oryzanol and vitamin E including tocopherols and tocotrienols. These nutritional compounds play an important part in preventing oxidative damage in foods and have a wide range of application in biological activities. The rice bran from red and purple rice has a higher concentration of phenolic and flavonoid concentrations than the lighter rice bran colour. Rice bran of white and light brown rice varieties commonly sold in the market has a total phenolic percentage of $30-50 \%$ (Min et al., 2012). The bran of rice also contains important bioactive phytochemicals including steryl ferulates including $\gamma$-oryzanol and its major components such as cycloartenyl ferulate (CAF), 24-methylenecycloartanyl ferulate (24mCAF), $\beta$-sitosteryl ferulate ( $\beta$-SF), and campesteryl ferulate. This compound has been extensively studied for their important role in pathology. The in vivo and in vitro studies of rice brain identified the role of phytosteryl ferulates which act as a mediator for anti 
inflammation by down regulating the inflammatory transcription factor nuclear factor kB (NF- kB) which in turn reduces the expression of inflammatory enzymes of COX-2, NOS and proinflammatory cytokines like IL-1 , IL- 6 and TNF- $\alpha$. The phytosteryl ferulates present in the bran helps in up-regulation of blood adiponectin level via indirect activation of peroxisomal proliferators-activated receptor (PPAR $\gamma$ ) through NF-кB inhibition (Islam et al., 2011). The bran also provides antioxidants including vitamin E, oryzanol, quality oil, protein, cholesterol lowering waxes and anti-tumor compounds like bran saccharide (Rohrer and Siebenmorgen, 2004; Chaudhary and Tran, 2001). The unsaponifiable portion of rice bran consists of two antioxidant groups, Tocotrienols and gamma $(\gamma)$-oryzanol. Tocotrienols belongs to vitamin E group and gamma $(\gamma)$-oryzanol has been widely studied for potential health benefits (IRRI). The bran also contains both soluble and insoluble fiber. This insoluble fiber adds to gastrointestinal track causing frequent stools and pass through more quickly, requiring less pressure to expel and absorbing bile acids to prevent their reabsorption in the body (Wells, 1993). The bran also reduces the serum cholesterol levels in the blood that help in lower of bad low-density lipoprotein (LDL) and increase good high-density lipoprotein (HDL) levels for cardiovascular health. Rice bran oil (RBO) significantly lowered the LDL/HDL ration by $19 \%$ over 4 weeks, effectively after a 2-week period (Berger et al., 2005). Traces elements like phosphorus, potassium, magnesium, calcium, manganese are present in bran. Magnesium improves the glycemic control and helps prevent insulin resistance. Rice bran provides energy boosting due to the presents of phytonutrients like CoQ10 and pangamic acid belonging to vitamin $\mathrm{B}$. These nutrients are vital for energy metabolism and electron transport in the mitochondria and served as an effective intercellular antioxidant. CoQ10 improves energy in the heart muscles. Gamma oryzanol is effective in burning fat and increasing the lean body mass. A number of studies have shown that $7 \%$ oryazanol in rice bran concentration in the diet of rats' shows reduction in bone loss and increase the risk of osteoporosis. The presence of Lutein and Zeaxanthin in bran also improves eyesight and reduces the chances of cataracts. The essential fatty acids in the bran like omega-3, omega-6, omega-9 and folic acid improve eye health. Vitamin $\mathrm{K}$ and Inositol Hexaphosphate
(IP6) helps in preventing stone formation in the kidney by removing the calcium from the blood and stored in bones. Inositol Hexaphosphate helps in inhabiting urinary calcium oxalate crystallization. Inositol, phospholipid and Vitamin B complex detoxifies the important parts of the human body including the liver, control liver cirrhosis and improve cell regeneration. The fiber helps in reducing and removing the toxics, improving optimum $\mathrm{pH}$ for digestion and allows frequent stool passage leads to prevent colon cancer. Natural antioxidants like tocopherols, tocotrienol and oryzanol are rich in the bran of black rice (Godber et al., 1994). The harmful effect of synthetic antioxidants butylated hydroanisole (BHA) and butylated hydroxytoluene (BHT) has increased the concern of people to search for natural antioxidants. This can be met if the importance and knowledge of rice bran are shares with the public. Studies on rice bran have shown that rice antioxidants at $500 \mathrm{ppm}$ provide the same amount of antioxidant as compared to the mixture of $\mathrm{BHA} / \mathrm{BHT}$ at $200 \mathrm{ppm}$ (Hettiarachchy et al., 1993). Oryzanol, tocopherol and tocotrienol prevent oxidative stress and lipid oxidation (Chiang et al., 2006). Phytosterols have shown to function as biologically active substrates that contribute in reducing the risk of human diseases (Tham, 1998). Biological functions of phytosterols have been demonstrated by cholesterol reducing properties and anticancer effects (Awd and Fink, 2000; Andersson et al., 2004). Typical representatives of phytosterols found commonly in plants (Akihisa et al., 1991) include sitosterol, stigmasterol and campesterol are shown in Figure 1. This compound has attracted much attention due to their nutritional properties as natural components of a regular diet (Eussen et al., 2011; Jones and Abumweis, 2009). Physterols have also attracted much attention in whole grains because increased in consumption of whole grain is associated with reduced risk of chronic disease (Liu, 2007). Phytochemicals containing whole grains such as sterol and phenolic compounds are the health benefits (Lu et al., 2011; Gani et al., 2012). In particular, rice is known to contain a unique phytosterols complement when consumed together with fruits and vegetables (Lloyd, 2000). Phytosterols might attribute to an important role in providing the functional benefits from consumption of rice. The typical methods used for the determination of phytosterols include gas 
liquid chromatography (Phillips et al., 1999) and high performance liquid chromatography (Kasama et al., 1987). Compositions of rice bran and bran oil are listed in Table 1 and Table 2.

\section{Rice Bran Saccharide and Its Capabilities}

Rice bran saccharide like Rice Bran Arabinoxylan Compound (RBAC) has proved clinically that it triple Natural Killer (NK) cell activity, increase $\mathrm{T}$ and $\mathrm{B}$ lymphocytes and demonstrate vital antioxidant and anti-inflammatory activities. An enzyme extracted from Shiitake mushroom using biotechnology has been patented for modifying RBAC, which is present in rice bran. As an immune modulator, BRM4 retains its effectiveness over time. Clinical trials have shown BRM4 is safe with no side effects. During the last 12 years of worldwide use, there are no reported cases of drug interactions. BRM4 is recognized as the gold standard immune product worldwide for people with seriously compromised immune systems (Daiwa Pharmaceutical, 2009).

Rice Bran Saccharide (RBS) a polysaccharide component contained in rice bran, exhibits anti-tumor capabilities (Godber et al., 2002). In a study on tumor prevention and suppression of tumor growth in rats, RBS was considered to suppress carcinogenesis and to prolong survival rate. If RBS can be extracted successfully, rice bran could be a source for a high-value pharmaceutical product (Takeshita et al., 1992). A number of studies on rice bran milling times, kernel thickness fraction, variety and environmental conditions have found

Table 1: The fatty acid composition of rice bran oil

\begin{tabular}{lcc}
\hline SI.No & Fatty acid & Percentage \\
\hline 1 & Palmitic acid & $15.0 \%$ \\
2 & Stearic acid & $1.9 \%$ \\
3 & Oleic acid & $42.5 \%$ \\
4 & Linoleic acid & $39.1 \%$ \\
5 & Linolenic acid & $1.1 \%$ \\
6 & Arachidic acid & $0.5 \%$ \\
7 & Behenic acid & $0.2 \%$ \\
\hline
\end{tabular}

Source: Rice Bran Oil variation in the levels of tocopherol, tocotrienol, and $\gamma$-oryzanol in rice varieties of southern U.S., AB647, Bengal, Cypress, Dellmati, LaGrue, Toro 2, and Wells (Bergman and $\mathrm{Xu}$, 2003). These studies identified that the content of phytochemicals appeared to be influenced by the variety and geographic location. Rohrer \& Siebenmorgen, (2004) in their study divided rough rice into three thickness fractions for rice varieties Cypress and Drew. It was noted that bran from thicker kernel fractions contained higher levels of nutraceutical than bran from thinner kernel fractions. In many tropical regions of the world, cereal grains, legumes or beans, roots and tubers are a major source of human diet (Emmy et al., 2008). Brown rice grains are rich in nutritional components like dietary fibers, phytic acids, vitamins $B, E$ and gamma amino butyric acid (GABA) than the ordinary milled rice grains.

\section{Gamma Amino Butyric Acid of Brown Rice}

Nutritional components such as dietary fibers, phytic acids, vitamins $B$ \& E, and Gamma Amino Butyric Acid (GABA) are rich among the brown rice varieties. These components are noted in the germ and bran layers (Champagne et al., 2004). GABA is a known non-protein amino acid that is widely distributed throughout the biological world of plants and mammalian tissues; also in bacteria and yeast (Wang, 2006; Komatsuzaki et al., 2007).

Table 2: Composition of rice bran

\begin{tabular}{llc}
\hline S. No & Constituent & Percentage \\
\hline 1 & Protein & $11.5-17.2 \%$ \\
2 & Starch & $10-55 \%$ \\
3 & Ash* & $8-17.7 \%$ \\
4 & Fiber & $6.2-31.5 \%$ \\
5 & Soluble fiber & $1.9-2.4 \%$ \\
6 & Insoluble fiber & $4.4-29 \%$ \\
7 & Phosphorus & $1.5-1.7 \%$ \\
8 & Potassium & $1.4-1.5 \%$ \\
9 & Magnesium & $0.78 \%$ \\
10 & Tocopherol (brown rice) & $22-31 \mathrm{ppm}$ \\
11 & Calcium & $0.02 \%$ \\
12 & Oryzanol (brown rice) & $500-720 \mathrm{ppm}$ \\
13 & Tocotrienol (brown rice) & $2.0-26.0 \mathrm{ppm}$ \\
\end{tabular}

(Source: Wells, 1993) 


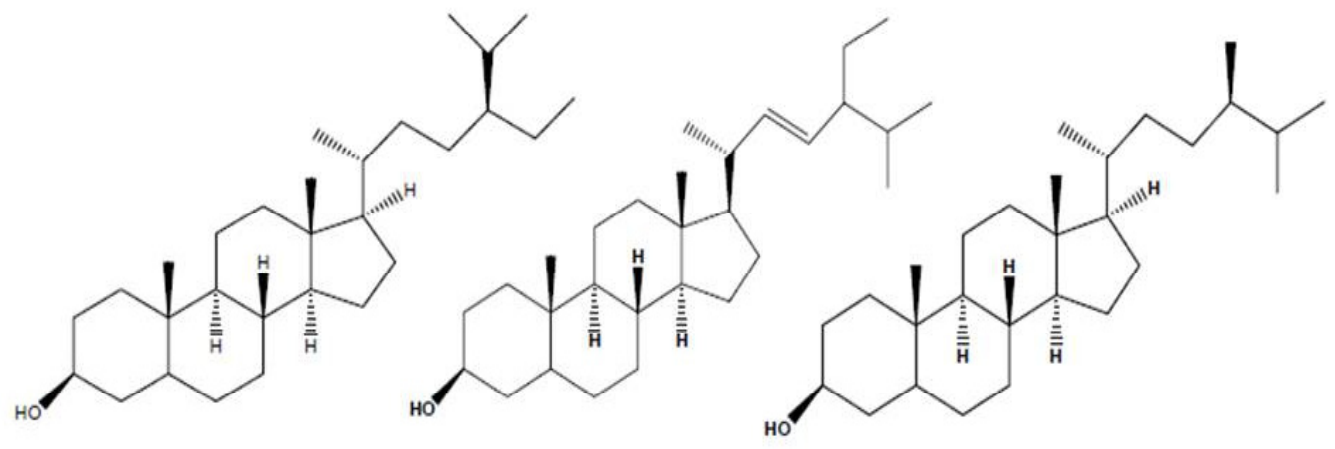

(1)

(2)

(3)

Fig. 1: Chemical structure of (1) Sitosterol, (2) Stigmasterol ( 3) Campesterol

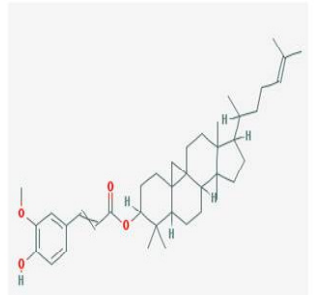

Oryzanol

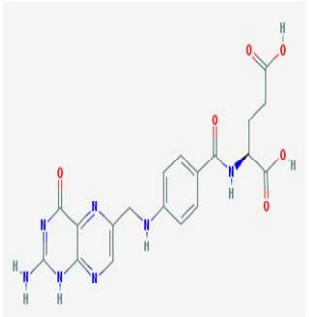

Folic acid

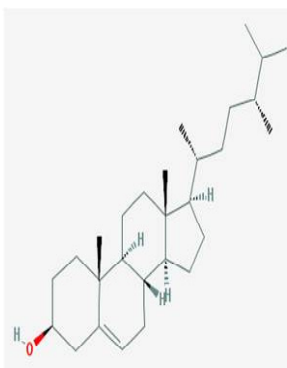

Campesterol

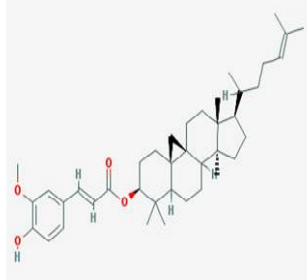

Gamma Oryzanol

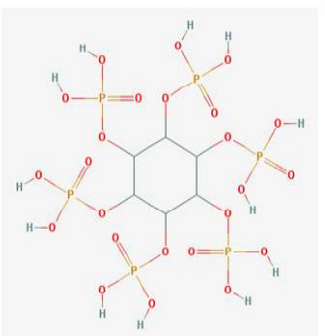

Inositol Hexaphosphate

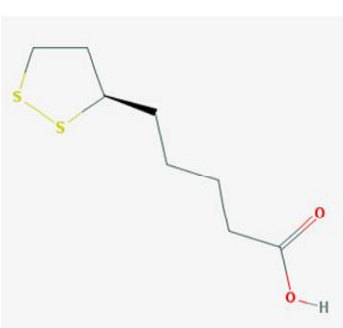

Alpha Lipoic acid

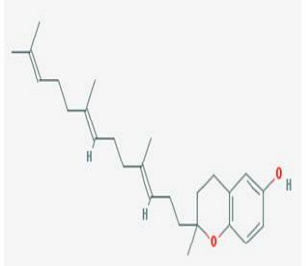

Tocotrienol

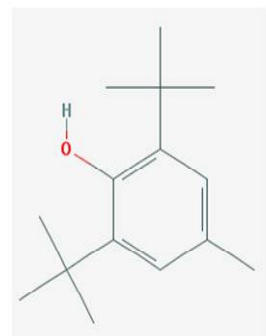

Butylated Hydroxytoluene

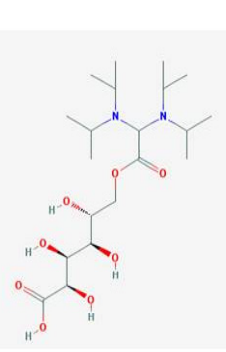

Pangamic acid

Zeaxanthin

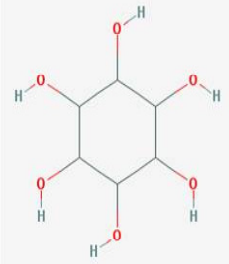

Inositol

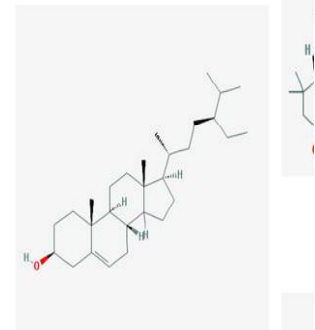

Phytosterol

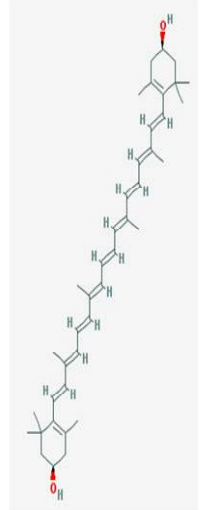

Fig. 2: Important compound present in dark purple rice varieties 
It plays a major role as inhibitory neurotransmitters in the central nervous system. Alteration in GABA levels in brain leads to the neurological disorders like seizures, Parkinson's disease and Stiff-man syndrome (Bao et al., 1995). A number of studies on $G A B A$ identified the role in treatment of various diseases. Administration of GABA through intravenous in animals (Stanton, 1963; Lacerda et al., 2003) and human (Elliott and Hobbiger, 1959) has reported reducing the blood pressure. Parallel studies on plant with high levels of GABA are effective for treatment of alcohol related symptoms (Cha and Oh, 2000), blood pressure regulation (Nakagawa and Onota, 1996) cardiovascular diseases and diabetes management (Hagiwara et al., 2004). Okada et al. (2000) in his study of GABA identified that intake of GABA for 8 consecutive weeks suppressed blood pressure, improved sleeplessness, and autonomic disorder observed during the menopausal or presenile period. GABA is synthesized by decarboxylation of L-glutamic acid, which is catalyzed by glutamate decarboxylase (GAD) enzyme and pyridoxal phosphate as a cofactor (Park et al., 1999). Glutamic acid also serves as a precursor for many other substances including glutathione (Wen et al., 2004) and arginine (Donald and Carl, 1950) in addition to GABA. There has been growing interest on the used of GABA as a bioactive component for food. Structures of some of the important compounds mentioned above are listed in Figure 2.

\section{Improvement}

The aromatic black glutinous rice of Manipur is poorly studied due to lack of knowledge of its medical and nutritional properties. Recently there has been some improvement work carried out in germplasms collection, characterization and evaluation of these aromatic rice cultivars for conservation, genetic divergence studies of wild and cultivated rice, genetic diversity study using isozyme analysis and analysis of variance (Medhabati et al., 2009; Medhabati et al., 2012; Medhabati et al., 2013a; Medhabati et al., 2013b). The aromatic black glutinous rice of Manipur has been characterized with 34 morphological characters. Medhabati et al. (2014) has developed a novel rice hybrid of "Chakhao Amubi and Basmati 370" to improve yield and provide better grain quality rice having high nutraceutical properties using anther culture development techniques of homozygous breeding lines of double haploid. These rice cultivars have been evaluated for eleven morpho-agronomic characters along with reaction to diseases and pests. The advancement in molecular biology, genomic research, transgenic breeding and molecular marker applications with conventional plant breeding practices has created the foundation for molecular plant breeding which will be very useful for the improvement of indigenous rice varieties including the aromatic black glutinous rice in Manipur.

\section{Future Concerns and Opportunities}

The importance of black rice bran has gained popularity among the general people as it provides a number of important compounds necessary for promoting antioxidants and health supplement. Antioxidants like anthocyanin are very productive in rice, which helps in fighting against heart disease, cancer, and associated diseases. Food and beverages industries could explore the potential of rice bran to boosts human health and provide supplementary nutrients to the human body as synthetic compounds have side effects. The demand for proteins of ingredients has been increasing which results in an increase in researches for identification of novel proteins obtained from numerous sources (El Nasri et al., 2007). The protein should possess the desirable functional and nutritional qualities as required in the food processing application. The people in the tropical countries consumed cereal grains, legumes or beans, roots and tubers as worthy human diet and supplement for human health (Phillips et al., 1999). There is an increasing demand for the domestic aromatic black glutinous rice in Manipur. Efforts need to be taken up for developing high yielding varieties without losing the grain quality characters, cooking quality and aroma. The improved varieties can export to Southeast and East Asian countries where there is a huge demand of aromatic glutinous rice. The advancement in transgenic crops has provided immense benefits in yield, better quality and resistance to biotic and abiotic factors, but the problem is environmental and agronomic impacts (Kansal and Sangha, 2013). This has lead to attracting global attention and debates. Therefore, crop improvement through novel hybridization 
technique using important germplasms has emerged as an ideal solution to meet the demand and provide nutritional properties for developing country like India.

\section{DISCUSSION}

The increase in health consciousness among the urban population and the requirement to improve the health status of the rural people has resulted in the increasing demands for health supplements from natural sources. A number of researches have been carried out to identify novel proteins obtained from various sources (Lamsal et al., 2007; Mu et al., 2009). The novel proteins should possess desirable function and nutritionals qualities to be accepted by food processing industries (Mu et al., 2009). The people in the tropical region mostly depend on cereal grains, legumes or beans, roots and tubers for daily diet (Lu et al., 2011). With the demand for food is increasing to meet the increasing human population, there is a need for a modern approach to improve the crop varieties. Farmers and agricultural scientist are looking for state of the art technologies like metabolomics to understand the details knowledge on the biochemical composition of crops products and if any changes during storage, transportation and processing in industrial units. The steps involve from food production to processing to have a significant influence on the quality of the crop when it reaches the consumers.

Rice bran is a valuable by product of rice milling that contains a large amount of nutritive compounds, including edible lipids. The rice grain contains $5 \%$ bran, of which $12-18.5 \%$ is oil. Rice bran oil is not so popular worldwide, but the demand is increasing. Rice bran oil contains a range of fats, with $47 \%$ monounsaturated, $33 \%$ polyunsaturated, and $20 \%$ saturated. A fraction of bran contains $12 \%-13 \%$ oil and highly unsaponifiable components (4.3\%). This includes tocotrienols (a form of vitamin), ammaoryzanol, and beta-sitosterol; helps in lowering of the plasma levels in lipid profile. Rice bran also contains a high level of dietary fibers betaglucan, pectin, gum and 4-hydroxy-3-methoxycinnamic acid (ferulic acid).

\section{CONCLUSION}

There is a growing interest for identification and synthesis of better nutraceutical rice for food and medicinal purposes. The demand of such compound is increasing in the last few decades, as people are more concern in plant base healthy food habit. Therefore, there is a huge gap between the requirement and the production. Hence, Chakhao can be utilize in nutritional medicine for improving the health status of the people and as a potential source of dietary antioxidants. Based on the above reviewed importance of rice nutraceutical, medicinally and therapeutically, Chakhao the dark purple scented rice of Manipur can hold a promising area of research, which aims at sustainable utilization of this staple crop. We can hope for the value added production and economic uplifting via exploring and utilizing its multifaceted potentialities for improving the health and social status.

\section{ACKNOWLEDGEMENT}

The authors thank the unknown peer reviewers for their valuable suggestion in improving the manuscript, Director IBSD, for providing the infrastructure facilities and Department of Science and Technology, New Delhi, India for the financial assistance. 


\section{REFERENCES}

1. Adom K. K., Liu R. H., Antioxidant activity of grains, Journal of Agricultural and Food Chemistry. 50(21): 6182-6187(2002).

2. Andersson S.W., Skinner J., Ellegard L., Welch A.A., Bingham S., Mulligan A., Andersson H., Khaw K.T. Intake of dietary plant sterols in inversely related to serum cholesterol concentration in men and women in the EPIC Norfolk populations: A cross sectional study, European Journal of Clinical Nutrition. (58):1378-1385(2004).

3. Akihisa T., Kokke W., Tamura T. Naturally occurring sterols and related compounds from plants, in Physiology and Biochemistry of Sterols, Patterson, G.W. and Nes, W.D., Eds., American Oil Chemists' Society, Champaign. 172-228(1991).

4. Awd A.B., Fink C.S., Phytosterols as anticancer dietary components: Evidence and mechanism of action, Journal of Nutrition. 130: 2127-2130(2000).

5. BaoJ., CheungW.Y., Wu J.Y., Brain L-glutamate decarboxylase. Inhibition by phosphorylation and activation by dephosphorylation, Journal Biological Chemistry. 270(12): 64646467(1995).

6. Berger A., Rein D., Schafer A., Monnard I., Gremaud G., Lambelet P., Bertoli C., Similar cholesterol lowering properties of rice bran oil, with varied ã-oryzanol, in mildly hypercholesterolemic men, European journal of Nutrition. 44(3): 163-173(2005).

7. Bergman C., Xu Z., Genotype and environment effects on tocopherol, tocotrienol, and ã-oryzanol contents of Southern US rice, Journal Cereal Chemistry. 80(4): 446449(2003).

8. Brower V., Nutraceuticals: poised for a healthy slice of the healthcare market?, Nature Biotechnology. 16: 728-731(1998).

9. ChaY.S., Oh S.H., Investigation of aminobutyric acid in chinese cabbages and effects of the cabbage diets on lipid metabolism and liver function of rats administered with ethanol, Journal of the Korean Society of Food Science and Nutrition. 29(3): 500-505(2000).

10. Champagne E.T., Wood D.F., Juliano
B.O., Bechtel D.B., The rice grain and its gross composition. In: Champagne ET (ed) Rice Chemistry and Technology. American Association of Cereal Chemists Press, Minneapolis, 77-107(2004).

11. Chaudhary R.C., Tran D.V., Specialty rice's of the world - a prologue. In: Specialty Rices of the World: Breeding, Production, and Marketing. FAO, Rome, Italy; and Oxford \& IBH Publishing Co. Pvt. Ltd., New Delhi, India, 3-14(2001).

12. Chiang A.N., Wu H.L., Yeh H.I., Chu C.S., Lin H., Ch L., Wei C. Antioxidant Effects of Black Rice Extract through the Induction of Superoxide Dismutase and Catalase Activities, In Lipid. 41(5): 794-803(2006).

13. Daiwa Pharmaceutical, Daiwa Health Development Introduces Double Strength BRM4 ${ }^{\mathrm{TM}}$ Rice Bran Arabinoxylan Compound (2009). Access from http://newhope360. $\mathrm{com} /$ health/daiwa-health-developmentintroduces-double-strength-brm4-rice-branarabinoxylan-compound

14. Dipti et al., The potential of rice to offer solutions for malnutrition and chronic diseases. Rice. 2012 5:16. doi:10.1186/19398433-5-16(2012).

15. Donald W.H., Carl M.L., The role of glutamic acid in arginine synthesis by lactobacillus arabinosus, The Journal of Biological Chemistry.185(1): 39-44(1950).

16. El Nasri N.A., Tinay El A.H., Functional properties of fenugreek (Trigonella foenum graecum) protein concentrate, Food Chemistry. 103: 582-589(2007).

17. Elliott K. A. C., Hobbiger F., GABA circulatory and respiratory effects in different species, Journal of Physiology.146: 70-84(1959).

18. Emmy H., Ki A., Normah H., Mohd E. N., Nutritional and amino acid contents of differently treated Roselle (Hibiscus sabdariffa L.) seeds, Food Chemistry. 111: 906-911(2008).

19. Eussen S.R.B.M., Feenstra T.L., Toxopeus I.B., Hoek-Stra J., Klungel O.H., Verhagen H., Van K.H.J., Rompelberg C.J.M. Costs and health effects of adding functional foods 
containing physterols/-stanols to statin therapy in the prevention of cardiovascular disease, European Journal of Pharmacology. 668: 91-100(2011).

20. Gani A., Wani S.M., Masoodi F.A., Hameed G. Whole-grain cereal bioactive compounds and their health benefits: A review, In Food Processing and Technology. 3: 1-10(2012).

21. Godber J.S., Wells J.H., Rice bran: as a viable source of high value chemicals, Louisiana Agriculture. 37(2): 13-17(1994).

22. Godber J. S., Xu Z., Hegsted M., Walker T., Rice and rice bran oil in functional foods development, Louisiana Agriculture. 45(4): 9-10(2002).

23. Gurdev K., Harnessing science and technology for sustainable rice based production systems. FAO Rice Conference. Rome, Italy, 12-13 February (2004) Access from http://www. fao.org/rice2004/en/pdf/khush.pdf

24. Hagiwara H., Seki T., Ariga T., The effect of pregerminated brown rice intake on blood glucose and PAI-1 levels in streptozotocin-induced diabetic rats, Bioscience Biotechnology and Biochemistry. 68: 444-447(2004).

25. Hettiarachchy N., Landers P.S., Griffin K., Kalapathy U., Utilization of rice bran protein in food, In Wells B.R., (Ed). Arkansas Rice Research Studies, Arkansas Agricultural Experiment Station Research Series. 439: 205-211(1993).

26. Islam M.S., Nagasaka R., .Ohara K., Hosoya T., Ozaki H., Ushio H. H., Biological abilities of rice bran-derived antioxidant phytochemicals for medical therapy, In Curr Top Med Chem. 11(14): 1847-1853(2011).

27. International Rice Research Institute (IRRI): Interesting facts on rice.

Available at http://www.irri.org.

28. Jones P.J., Abumweis S.S., Phytosterols as functional food ingredients: Linkages to cardiovascular disease and cancer, Current Opinion in Clinical Nutrition and Metabolic Care. 12: 147-151(2009).

29. Juliano B., Rice Chemistry and Technology, American Association of Cereal Chemists, SA. 757(1985).

30. Kansal M., Sangha Gurinder K., Ecological Impact of Genetically Modified Crops, Research Journal of Recent Sciences. 2:
1-4 (2013).

31. Kasama T., Byun D.S., Seyama Y., Quantitative analysis of sterols in serum by high performance liquid chromatography: Application to the biochemical diagnosis of cerebrotendinous xanthomatosis, Journal of Chromatography A. 400: 214-246(1987).

32. Komatsuzaki N., Tsukahara K., Toyoshima H., Suzuki T., Shimizu N., Kimura T., Effect of soaking and gaseous treatment on GABA content in germinated brown rice, Journal of Food Engineering. 78( 2): 556-560(2007).

33. Lacerda J.E., Campos R.R., Araujo G.C., Andreatta-Van L., Eyen S., Lopes O.U., Guertzenstein, P.G. Cardiaovascular responses to microinjections of GABA or anesthetics into the rostral ventrolateral medulla of conscious and anaesthetized rats, Brazilian Journal of Medical and Biological Research. 36(9): 1269-1277(2003).

34. Lamsal B., Koegel R., Gunasekaran S., Some physicochemical and functional properties of alfalfa soluble leaf proteins, LWT-Food Science and Technology. 40: 1520-1526 (2007).

35. Liu R. H., Whole grain phytochemicals and health, J. Cereal Sci. 46(3): 207-219 (2007).

36. Lloyd B.J., Siebenmorgen T.J., Beers K.W., Effect of commercial processing on antioxidants in rice ban, Cereal Chemistry. 77: 551-555 (2000).

37. Lu T.J., Chen H.N., Wang H.J. Chemical constituents, dietary fiber, and ã-oryzanol in six commercial varieties of brown rice from Taiwan, Cereal Chemistry. 88:463- 466 (2011).

38. Majumdar G.P., Banerji S. C., Krsi-Parasara, The Asiatic Society, Calcutta, West Bengal, India. 88(1960).

39. Medhabati K., Sanjukta R.K., Rajiv D.K., Rohinikumar M., Conservation of Indigeneous Rice Biodiversity of Manipur, Proceedings of International Conference on Energy and Environment. 659 -665(2009).

40. Medhabati K., Rajiv D.K., Rohinikumar M., Henary Ch., Dikash Th., Study on Analysis of Variance on the indigenous wild and cultivated rice species of Manipur Valley, International Journal of Advancements in Research \& Technology. 1: 1-5(2012). 
41. Medhabati K., Nongalleima Kh., Rajiv D.K., Sunitibala H., Establishing genetic diversity among indigenous cultivated and wild rice species of Manipur using Isozyme analysis, Advances in Applied Science Research. 4: $309-314(2013)$.

42. Medhabati K., Rajiv D.K., Rohinikumar M., Sunitibala H., Dikash Th., Genetic Divergence in Indigenous Wild and Cultivated Rice Species of Manipur Valley, ISRN Genetics,16(2013).

43. Medhabati K., Rajiv D.K., Henary Ch., Dikash Th., Sunitibala H., Androgenic Callus Induction of the Indica Rice Hybrid of Chakhao Amubi and Basmati 370, International Research Journal of Biological Sciences. 3(4): 73-79 (2014).

44. Min B., Gu L., McClung A.M., Bergman C.J., Chen M., Free and bound total phenolics, procyanidin and anthocyanin profiles and their antioxidant capacities in whole grain rice (Oryza sativa L.) of different bran colors, Food Chemistry. 133: 715-722 (2012).

45. Mu T., Tan S., Xue Y., The amino acid composition, solubility and emulsifying properties of sweet potato protein, Food Chemistry. 112: 1002-1005 (2009).

46. Nakagawa K., Onota A., Accumulation of gamma aminobutyric acid (GABA) in the rice germ, Food Processing. 31:43-46(1996).

47. Okada T., Sugishita T., Murakami T., Murai H., Saikusa T., Horio T. Effect of the defatted rice germ enriched with GABA for sleeplessness, depression, autonomic disorder by oral dministration, Nippon Shokuhin Kagaku Kougaku Kaishi. 47(8): 596- 603 (2000).

48. Park J.K., Jin S.H., Choi K.H., Ko J.H, Baek N.I., Choi S.Y., Cho S.W., Choi K.J., Nam K.Y., Influence of ginsenosides on the kainic acidinduced seizure activity in immature rats, Journal of Biochemistry and Molecular Biology. 32:339-344 (1999).

49. Phillips K.M., Ruggio D.M., Bailey J.A., Precise quantitative determination of phytosterols, stanols, and cholesterol metabolites in human serum by capillary gas-liquid chromatography, Journal of Chromatography B.732: 17- 29 (1999).

50. Raju R.R., Telugu folk medicine, Folklore. 25(8): 145-155(1984).
51. Rohrer C.A., Siebenmorgen T.J., Nutraceutical concentrations within the bran of various rice kernel thickness fractions, Biosystems Engineering. 88(4): 453-460(2004).

52. Singh R., Shahi Sudhir K., Mishra D.J., and Mishra U.K., Emerging Trends in Indian Agriculture: A Review, Research Journal of Recent Sciences. 2: 36-38 (2013).

53. Stanton H.C., Mode of action gamma aminobutyric acid on the cardiovascular system, Arch Int Pharmacodyn The. 143: 195- 204 (1963).

54. Stephen De Felice, S.L., FIM Rationale and Proposed Guidelines for the Nutraceutical Research \& Education Act-NREA Foundation for Innovation in Medicine (2002). Available at http://www.fimdefelice.org/archives/arc. researchact.html

55. Takeshita M., Nakamura S., Makitam F., Ohwadam S., Miyamoto Y., Morishita Y. Antitumor effects of RBS (Rice Bran Saccharide) on ENNG-induced carcinogenesis, Biotherapy. 4(2): 139-145 (1992).

56. Tham D.M., 1998. Potential health benefits of dietary phytoestrogens: A review of the clinical, epidemiological, and mechanistic evidence, The Journal of Clinical Endocrinology and Metabolism. 83: 2223-2235(1998).

57. Vir O., Singh B.B., Tomar B.S., Specialty rices for therapeutic purposes, good health and processed food products. In: Proceedings of the National Symposium on Basmati Rice Research: Current Trends and Future prospects, 6-7 September, SVBP University of Agriculture and Technology, Meerut, Uttar Pradesh, India. 65-72 (2005).

58. Wang H.F., Tsai Y.S., Lin M.L., Ou A.S.M., Comparison of bioactive components in GABA tea and green tea produced in Taiwan, Food Chemistry. 96(4): 648- 653 (2006).

59. Wells J.H., Utilization of rice bran and oil in human diets, Louisiana Agriculture. 36(3): 5- 8(1993).

60. Wen S., Zhang T., Tan T., Utilization of amino acids to enhance glutathione production in Saccharomyces cerevisiae, Enzyme Microbiology Technology. 35(6-7): 501-507 (2004).

61. Zeisel S.H., Regulation of Nutraceuticals, Science. 285(5435):1853-1855 (1999). 